\title{
Community-based specialist palliative care is associated with reduced hospital costs for people with non-cancer conditions during the last year of life
}

\author{
Katrina Spilsbury ${ }^{1}$ (iD and Lorna Rosenwax $2^{*}$
}

\begin{abstract}
Background: Community-based palliative care is associated with reduced hospital costs for people dying from cancer. It is unknown if reduced hospital costs are universal across multiple life-limiting conditions amenable to palliative care. The aim of this study was to determine if community-based palliative care provided to people dying from non-cancer conditions was associated with reduced hospital costs in the last year of life and how this compared with people dying from cancer.

Method: A retrospective population-based cohort study of all decedents in Western Australia who died January 2009 to December 2010 from a life-limiting condition considered amenable to palliative care. Hospital costs were assigned to each day of the last year of life for each decedent with a zero cost applied to days not in hospital. Day-specific hospital costs averaged over all decedents (cohort averaged) and decedents in hospital only (inpatient averaged) were estimated. Two-part models and generalised linear models were used.

Results: The cohort comprised 12,764 decedents who, combined, spent 451,236 (9.7\%) days of the last year of life in hospital. Overall, periods of time receiving community-based specialist palliative care were associated with a $27 \%$ decrease from A\$112 (A\$110-A\$114) per decedent per day to \$A82 (A\$78-A\$85) per decedent per day of CA hospital costs. Community-based specialist palliative care was also associated a reduction of inpatient averaged hospital costs of 9\% (7\%-10\%) to A $\$ 1030$ per hospitalised decedent per day. Hospital cost reductions were observed for decedents with organ failures, chronic obstructive pulmonary disease, Alzheimer's disease, Parkinson's disease and cancer but not for motor neurone disease. Cost reductions associated with community-based specialist palliative care were evident 4 months before death for decedents with cancer and by one to 2 months before death for decedents dying from other conditions.
\end{abstract}

Conclusion: Community-based specialist palliative care was associated with hospital cost reductions across multiple life-limiting conditions.

Keywords: Palliative care, Heart failure, Renal failure, Liver failure, Chronic obstructive pulmonary disease, Cancer, Alzheimer's disease, Parkinson's disease, Hospital costs

\footnotetext{
* Correspondence: L.Rosenwax@curtin.edu.au

${ }^{2}$ School of Occupational Therapy and Social Work, Faculty of Health Sciences,

Curtin University, GPO Box U1987, Perth 6845, Australia

Full list of author information is available at the end of the article
} 


\section{Background}

Health care at the end of life has been estimated to account for around $10-15 \%$ of total health care expenditure in developed countries [1-3]. Health care costs increase sharply as death approaches which has raised concerns about the use of unnecessary medical interventions during the end-of-life phase, although patient social and religious determinants for more aggressive end of life care have been reported $[4,5]$. Yet, a recent Italian clinical trial that randomised prostate cancer patients into systematic or on-demand palliative care reported that patients delivered systematic palliative care spent more days in hospice care and received less chemotherapy in the last month of life [6].

In addition to improved patient quality of life measures, specialist palliative care, both hospital-based and community (home)-based, have consistently been associated with reduced health care costs, mostly from a provider viewpoint. A recent systematic review identified 46 studies that compared costs of a palliative care intervention relative to a comparator group with the majority of studies reporting a statistically significant decrease in provider costs for the palliative care intervention [7].

Most of these published studies estimating the cost of palliative care relative to other types of care focused on cancer patients. There are few studies that have compared hospital costs associated with palliative care intervention over the last year of life at a population-level for both cancer and non-cancer conditions. An early US study of over 50,000 Medicare enrolees aged 65 years and over found reduced hospital expenditures in cancer patients who received hospice care but not for noncancer conditions, however, only univariate analyses were performed [8].

We hypothesised that specialist palliative care provided in the community to people dying from noncancer conditions would also be associatied with reduced hospital costs in the last year of life as has been demontrated for cancer. The benefits of specialised palliative care for patients with various non-cancer life limiting conditions are now widely reported and include reduced hospitalisation, improved symptom burden and quality of life [9-13]. Despite this, palliative care in noncancer life limiting conditions is generally considered as under-utilised $[14,15]$. In Western Australia (WA), for example, around $70 \%$ of people with cancer accessed specialist palliative care in the last year of life compared to $14 \%$ of people who died from other conditions considered amenable to palliative care [16].

In Australia, the majority of hospital and palliative care funding is provided by state governments. The WA governament has taken a different approach to other Australian states with the provision of relatively fewer hospital inpatient pallitative care beds and greater funding for community-based specialist palliative care. The aim of this paper was to estimate from a provider perspective, whether receiving community-based specialist palliative was associated with reduced hospital costs in a variety of non-cancer life-limiting conditions considered amenable to palliative care. These findings will provide evidence for service providers and health care planners make more efficient use of the health care resources and to advocate for more equitable access of palliative care across all life-limiting conditions.

\section{Methods \\ Study design}

This was a retrospective cohort study of the last year of life of all people who died in WA from 1 January 2009 to 31 December 2010 with a cause of death potentially amenable to receiving palliative care; namely cancers, heart failure, renal failure, liver failure, chronic obstructive pulmonary disease, Alzheimer's disease, motor neurone disease, Parkinson's disease, Huntington's disease and HIV/AIDS. Approvals to conduct this study were granted by Human Research Ethics Committees at the WA Department of Health (\#2012/76, 01/02/2013) and Curtin University (53/2012, 06/06/2012).

\section{Cohort selection}

A de-identified linked extraction of death records, hospital records and community-based care records of all decedents spanning the last 2 years of life was obtained from the Data Linkage Branch at the WA Department of Health. Further details on the selection of this cohort and health service use in the last year of life have been reported previously[16, 17]. Briefly, it consisted of 12 , 817 people who died during the 2 year study period in WA and who had mention on Part I of their death certificate of one or more of the ten disease conditions considered amenable for palliative care as defined by Rosenwax et al.[18]. When a decedent had more than one of the ten conditions of interest on Part 1 of their death certificate, then the most antecedent condition was assigned as the principal condition.

\section{Exposure variable: community-based specialist palliative care}

The community-based specialist palliative care in this study was provided by Silver Chain WA which supplied over $90 \%$ of referred community-based specialist palliative care in WA, although this was mostly restricted to major metropolitan areas [19]. WA is the largest state of Australia $\left(2.5\right.$ million $\left.\mathrm{km}^{2}\right)$ with a population of 2.6 million that is concentrated in the capital city, Perth, and the south-west corner of the state. A multidisciplinary team of palliative care clinicians and nurses, allied health professionals and volunteers provide home nursing care, 
counselling, respite options, practical support and links to other services with the aim of enabling people with a life limiting illness to remain at home. A palliative nurse consultancy service was available to residential care facilities where client care is managed around the clock by registered nurses. This service included advice, assessment, staff education and telephone follow-up to meet the needs of specific clients. A palliative care rural telephone advisory service provided specialist palliative care advice to local rural service providers $24 \mathrm{~h}$ per day. Client dates of enrolment and disenrollment were used to define periods of time receiving community-based specialist palliative care. It was possible for decedents to have multiple periods of palliative care enrolment if their symptoms were of a relapsing and remitting nature. Clients were discharged from the service after 1 month if they were not available for regular review.

\section{Outcome measures: day-specific hospital costs}

Each day of the last year of life for every decedent was assigned a day number ranging from 1 (365 days before death) to 365 (day of death). A hospital cost was applied to each day of the last year of life for every decedent with days not spent in hospital considered to have incurred zero costs. From these day-specific hospital costs, two cost-based outcome measures were defined. The first was the mean day-specific hospital cost averaged over all decedents whether they were in hospital or not. We refer to this mean day-specific hospital cost as being a cohort averaged (CA) hospital cost. This type of cost estimate is a reflection of both the decision to go to hospital and the actual costs once admitted. The second outcome measure was a mean day-specific hospital cost averaged over only decedents who were in hospital on that particular day. These costs are a reflection of hospital costs once admitted and these are referred to as inpatient averaged (IA) hospital costs.

The Australian Refined-Diagnostic Related Groups (AR-DRGs) system was used to estimate day-specific acute care hospital costs [20]. Component costs for acute episodes of care for each AR-DRG over the study period were obtained from National Hospital Cost Data Collection (NHCDC) reports [21, 22]. Fixed hospital costs included costs of operating room procedures, specialist procedure suites, critical care, pharmacy, pathology, imaging, allied health professionals and emergency department. Fixed costs were considered to have mostly been incurred during the initial period of hospital stays [23]. A daily fixed cost was estimated by fitting the fixed costs to a decreasing exponential distribution where the shape parameter was a function of the actual or national average length of stay such that $99.9 \%$ of fixed costs were distributed by the end of the hospital stay. Variable costs included staff salaries and on-costs, hotel costs, supplies and depreciation and were considered to have been incurred at a steady rate over the actual length of stay. Daily fixed and variable costs were summed to generate a day-specific hospital cost per decedent per day. For subacute care hospital stays, the WA average daily cost estimated from the NHCDC Round 15 (2010-2011) report and was assigned as $\$ 844$ for rehabilitation, $\$ 1051$ for palliative care, $\$ 815$ for geriatric evaluation and management, $\$ 1162$ for psychogeriatric care and $\$ 1012$ for maintenance [24]. All costs are in Australian dollars (\$A) and were adjusted for health inflation and standardised to the 2010-2011 financial year. On 31st December 2011, \$A1 was equivalent to \$US1 and Euro $€ 0.79$. The costs of hospital emergency department presentations were not included in this study.

\section{Decedent factors}

Marital status was classified as partnered or not/unknown. Decedent's residential locations were used to assign accessibility categories based on the Australian ARIA+ index that takes into account road distance measurements to the nearest service centres and population size [25]. Type of residence was classified as a private residence, residential aged care facility (RACF) or other. Changes in a decedents' marital status, place of residence, accessibility to services and community-based specialist palliative care status over the last year of life were recorded as time-varying covariates.

Comordity was estimated from hospital inpatient medical records over the last 2 years of life by summing the number of the 31 medical conditions identified by Elixhauser [26] based on algorithms created by Quan [27]. The underlying cause of death was excluded from the calculation of the number of comorbid conditions. Comorbidity for decedents without hospital admissions in the last 2 years of life was estimated from the death certificate.

\section{Statistical methods}

Data were structured so that each decedent had 365 observations representing their last year of life. Each day was assigned as being a day of a hospital stay and/or community-based specialist palliative care or not. Dates were permitted to overlap, for example, a day coded as a hospital stay could also be a community-based specialist palliative care day if it fell between palliative care enrolment and disenrollment service dates. Decedents with incomplete demographic information were excluded from further analysis. Locally weighted scatterplot smoothing was used to produce unadjusted curves of the mean daily hospital costs over the last year of life.

Cohort averaged daily hospital costs were modelled as a mixed discrete-continuous random variable with a mass point at zero. A two part model was fitted with the first part as a binary choice model of being in hospital 
or not (zero versus non-zero hospital costs) on any 1 day and the second part was conditional on being in hospital that day and used a generalised linear model with a reciprocal link and gamma distribution. The combined prediction was computed as the product of the probability of a hospital admission and the expected value of hospital costs conditional upon a positive cost.

Inpatient averaged mean daily hospital costs were modelled using generalised linear models with inverse Gaussian distribution and inverse quadratic link. Minimisation of the deviance, Akaike and Bayesian information criteria and the modified Park test were used to identify the best fitting distribution and link. Fractional polynomial transformations of variables were used when required. Additional explanatory power of interaction terms was assessed by the difference in model deviance values. Undue influence of individual observations on the model fit were tested and the model fit assessed by plotting Anscombe residuals against log variance. Standard errors were calculated using the clustered sandwich estimator to account for intragroup correlation and the Sidak correction was applied when estimating multiple marginal means. All analysis was performed using Stata 14 (College Station, TX).

\section{Results}

The cohort of decedents with underlying causes of death amenable to palliative care comprised 12,817 individuals as reported previously [16]. After excluding 34 decedents with incomplete demographic information and 19 decedents with Huntington's disease or HIV/AIDS due to small numbers, there remained 12,764 decedents in this study cohort. Combined, the cohort spent 451,236 (9.7\%) days of the last year of life as hospital inpatients for a total hospital cost of A\$503 million. Summary characteristic of the cohort are presented in Table 1 . The mean and median total hospital costs per decedent in the last year of life and averaged over all decedents were AU\$39,369 (SD 41,818) and $\mathrm{A} \$ 28,182$ (IQR 10,732-53,645) respectively. Community-based specialist palliative care was accessed by 3884 (30.4\%) decedents during the last year of life and this accounted for $6.6 \%$ of days in the last year of life (Table 1). Ten per cent $(n=1269)$ of the cohort were not admitted to hospital in the last year of life.

\section{Cohort averaged (CA) hospital costs}

The crude CA hospital cost averaged of the last year of life was A\$108 (SD 414) per decedent per day. However, this varied with closeness to time of death and ranged from $\mathrm{A} \$ 42$ (SD 256) 1 year before death to $\mathrm{A} \$ 602$ (SD 714) per decedent per day at time of death. The greatest differences in crude CA hospital costs by communitybased specialist palliative care status were observed close to the time of death (Fig. 1Ai). Decedents with liver failure had the highest unadjusted CA hospital costs close to the time of death while those with Alzheimer's disease and Parkinson's disease had the lowest (Fig. 1Aii). Higher crude CA hospital costs were also observed in decedents who were younger, male, partnered, had private health insurance, lived in a private residence and had multiple comorbidity (Table 1).

After adjusting for age, comorbidity and other potentially confounding variables in a two part main effects model, community-based specialist palliative care was associated with an average $27 \%$ reduction in CA hospital costs over the last year of life. This equated to a $\mathrm{A} \$ 30$ (95\%CI 26-34) reduction per decedent per day relative to periods of time not receiving community-based specialist palliative care (Table 1). Decedents dying from heart failure, Alzheimer's disease and Parkinson's disease had significantly lower average CA hospital costs relative to decedents with cancer. Adjusted CA hospital costs for decedents with liver failure were A\$14 per decedent per day lower than costs for decedents with cancer; a reversal of the earlier crude cost findings. Reduced CA hospital costs were also noted with increasing age at death, having a partner, not having private health insurance, living in a residential aged care facility and having less comorbidity.

However, a significant three-way interaction was observed between closeness to time of death, cause of death and community-based specialist palliative care which means that a single cost value cannot explain the associations adequately. Averaged over all causes of death, the association of community-based specialist palliative care with reduced CA hospital costs became evident at around 120 days before death (Fig. 2a). When stratified by cause of death, decedents with cancers showed this reduction earlier, at around 140 days before death (Fig. 2b). For decedents with heart failure, renal failure, chronic obstructive pulmonary disease and Parkinson's disease, significantly reduced CA hospital costs associated with community-based specialist palliative care became apparent around 45 days before death (Fig. 2c to e, h). Decedents with liver failure had reduced CA hospital costs in the fourth to second last months of life with the hospital costs converging around death (Fig. 2f). Decedents with motor neurone disease (MND) showed little difference in CA hospital costs with or without community-based specialist palliative care (Fig. 2g).

\section{Inpatient averaged (IA) hospital costs}

The crude IA hospital cost was A $\$ 1114$ per hospitalised decedent per day, although this varied with closeness to death and underlying cause of death (Fig. 1Bi and Bii). Being enrolled in community-based specialist palliative care at the time of hospitalisation consistently showed a lower crude IA hospital costs over the last year of life. 
Table 1 Cohort characteristics at death and the crude and adjusted cohort averaged hospital cost estimates by decedent characteristics

\begin{tabular}{|c|c|c|c|c|c|c|c|c|c|}
\hline \multirow{2}{*}{\multicolumn{4}{|c|}{ Decedent status at time of death ( $N=12,764$ decedents) }} & \multicolumn{6}{|c|}{ Cohort averaged cost per decedent per day ( $N=4,658,860$ days) } \\
\hline & & & & \multirow[t]{2}{*}{$\%$ days $^{b}$} & \multicolumn{2}{|c|}{ Crude A\$ } & \multicolumn{3}{|c|}{ Adjusted $^{a} \mathrm{~A} \$$} \\
\hline \multicolumn{2}{|l|}{ Characteristic } & $\mathrm{n}$ & $\%$ & & Mean & SD & Mean & $95 \% \mathrm{Cl}$ & $p$-value \\
\hline \multirow[t]{2}{*}{ Accessed community palliative care } & No & 8880 & 69.6 & 93.4 & 103 & 412 & 112 & $110-114$ & ref \\
\hline & Yes & 3884 & 30.4 & 6.6 & 181 & 438 & 82 & $78-85$ & $<0.001$ \\
\hline \multirow[t]{5}{*}{ Age group (years) } & $<60$ & 1640 & 12.8 & 12.8 & 146 & 521 & 119 & $113-125$ & ref \\
\hline & $60-69$ & 1995 & 15.6 & 15.6 & 127 & 473 & 110 & $105-115$ & 0.011 \\
\hline & $70-79$ & 3200 & 25.1 & 25.1 & 114 & 434 & 105 & $102-109$ & $<0.001$ \\
\hline & $80-89$ & 4208 & 33.0 & 33.0 & 96 & 363 & 107 & $103-110$ & $<0.001$ \\
\hline & $90+$ & 1721 & 13.5 & 13.5 & 67 & 281 & 98 & $92-104$ & $<0.001$ \\
\hline \multirow[t]{2}{*}{ Sex } & Male & 6910 & 54.1 & 54.1 & 113 & 434 & 108 & $105-110$ & ref \\
\hline & Female & 5854 & 45.9 & 45.9 & 101 & 390 & 108 & $106-111$ & 0.742 \\
\hline \multirow[t]{2}{*}{ Partnered } & No & 6826 & 53.5 & 48.3 & 100 & 392 & 113 & $110-116$ & ref \\
\hline & Yes & 5938 & 46.5 & 51.7 & 115 & 434 & 104 & $102-106$ & $<0.001$ \\
\hline Accessibility & Major cities & 8769 & 68.7 & 69.0 & 109 & 413 & 108 & $106-110$ & ref \\
\hline \multirow[t]{4}{*}{ index } & Inner regional & 2120 & 16.6 & 16.2 & 100 & 404 & 102 & $97-106$ & 0.009 \\
\hline & Outer regional & 1218 & 9.5 & 9.3 & 113 & 414 & 113 & $106-119$ & 0.188 \\
\hline & Remote & 425 & 3.3 & 3.8 & 114 & 416 & 114 & $103-126$ & 0.300 \\
\hline & Very remote & 232 & 1.8 & 1.7 & 116 & 534 & 104 & $88-119$ & 0.563 \\
\hline \multirow[t]{2}{*}{ Private health insurance } & No & 8225 & 64.4 & 64.4 & 94 & 385 & 101 & $99-103$ & ref \\
\hline & Yes & 4539 & 35.6 & 35.6 & 134 & 462 & 119 & $115-122$ & $<0.001$ \\
\hline \multirow[t]{3}{*}{ Type of residence } & Private & 9755 & 76.4 & 79.1 & 119 & 440 & 112 & $110-114$ & ref \\
\hline & RACF & 2711 & 21.2 & 18.2 & 61 & 281 & 81 & $76-86$ & $<0.001$ \\
\hline & Other /NFA & 298 & 2.3 & 2.7 & 102 & 376 & 110 & $97-124$ & 0.761 \\
\hline \multirow[t]{8}{*}{ Underlying cause of death } & Cancers & 7392 & 57.9 & 57.9 & 117 & 428 & 112 & $109-114$ & ref \\
\hline & Heart failure & 2017 & 15.8 & 15.8 & 92 & 400 & 98 & $93-103$ & $<0.001$ \\
\hline & Renal failure & 1138 & 8.9 & 8.9 & 133 & 446 & 110 & $104-117$ & 0.660 \\
\hline & COPD & 1089 & 8.5 & 8.5 & 95 & 401 & 108 & $101-115$ & 0.295 \\
\hline & Alzheimer's & 605 & 4.7 & 4.7 & 37 & 216 & 88 & $73-103$ & 0.003 \\
\hline & Liver failure & 206 & 1.6 & 1.6 & 131 & 527 & 98 & $85-111$ & 0.038 \\
\hline & MND & 136 & 1.1 & 1.0 & 77 & 317 & 99 & $79-119$ & 0.202 \\
\hline & Parkinson's & 181 & 1.4 & 1.4 & 48 & 244 & 85 & $70-100$ & 0.001 \\
\hline \multirow[t]{6}{*}{ No. comorbid conditions } & None & 2526 & 19.8 & 19.8 & 68 & 307 & 67 & $64-70$ & ref \\
\hline & One & 2834 & 22.2 & 22.2 & 80 & 354 & 83 & $80-86$ & $<0.001$ \\
\hline & Two & 2344 & 18.4 & 18.4 & 96 & 387 & 101 & $97-105$ & $<0.001$ \\
\hline & Three & 1745 & 13.7 & 13.7 & 114 & 428 & 116 & $111-121$ & $<0.001$ \\
\hline & Four & 1222 & 9.6 & 9.6 & 141 & 495 & 139 & $132-146$ & $<0.001$ \\
\hline & Five or more & 2093 & 16.4 & 16.4 & 182 & 539 & 169 & $163-176$ & $<0.001$ \\
\hline
\end{tabular}

RACF residential aged care facility, COPD chronic obstructive pulmonary disease, MND motor neurone disease, $S D$ standard deviation, NFA no fixed address, $A \$$

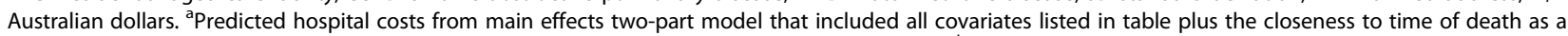
3,3 fractional polynomial transformation of day and the number of previous hospital admissions. ${ }^{\mathrm{b}}$ The percentage of days of the last year of life that decedents spent in each characteristic state. This varies from the percentage at time of death for characteristics which changed over the last year of life

The crude IA hospital costs stratified by the underlying cause of death showed a more variable pattern. IA hospital costs associated with cancer and Alzheimer's disease were consistent over the last year of life at around $\mathrm{A} \$ 1150$ and $\mathrm{A} \$ 1100$ per hospitalised decedent/per day respectively regardless of closeness to time of death. In contrast, the three types of organ failure, Parkinson's disease and COPD all showed increasing IA hospital costs with closeness to time of death. Higher crude IA hospital costs were also observed in decedents who 


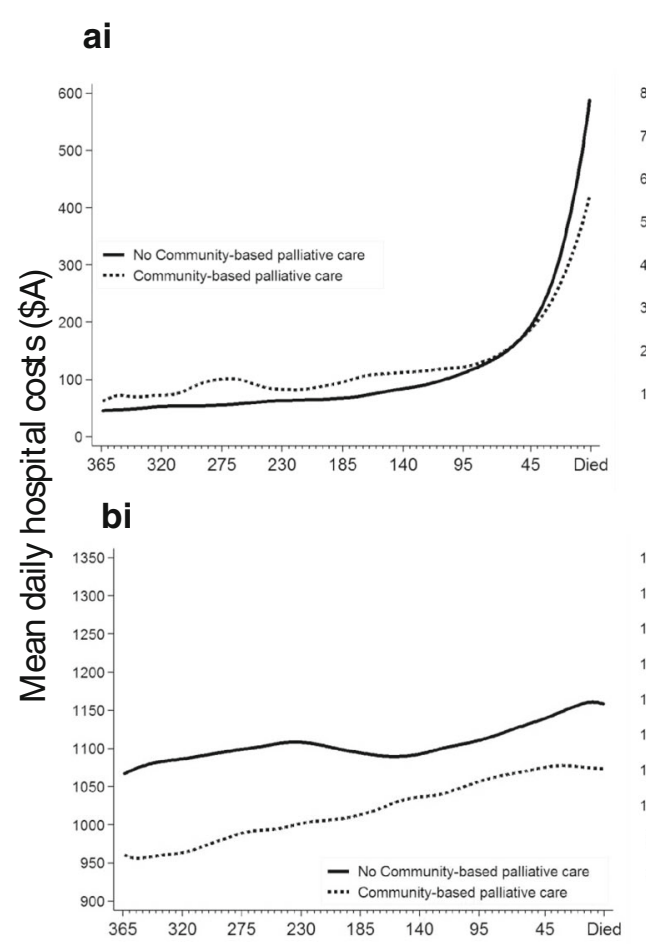

aii

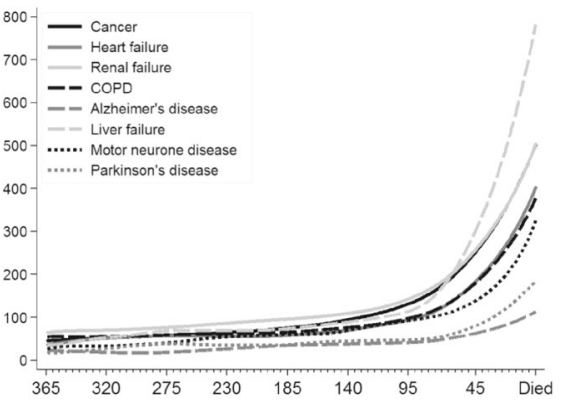

bii

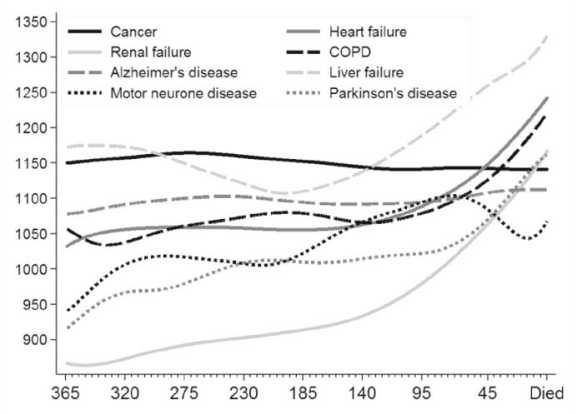

Days before death

Fig. 1 Crude cohort averaged and inpatient averaged day-specific hospital costs by cause of death and community-based palliative care. Locally weighted scatterplot smoothing of day-specific hospital costs over the last year of life as a cohort averaged and $\mathbf{b}$ inpatient averaged and stratified by i) periods of time receiving or not receiving community-based palliative care and ii) principal underlying cause of death

were younger, male, partnered, had private health insurance, lived in a private residence and had multiple comorbidity (Table 2).

After adjusting for other decedent factors associated with IA hospital costs and averaged over the year, IA hospital costs for hospitalised decedents who were receiving community-based specialist palliative care at the time of admission was $\mathrm{A} \$ 1030$ per decedent per day over the last year of life. This was a reduction of A\$96 (95\%CI 84- 107) per hospitalised decedent per day, equivalent to a $9 \%(95 \% \mathrm{CI} 7-10)$ reduction relative to decedents hospitalised during periods of time not receiving community-based specialist palliative care (Table 2). Reduced IA hospital costs were also noted for decedents who were older, female and with less comorbidity.

However, further modelling that included significant interaction terms showed that the reduction in IA hospital costs associated with community-based specialist palliative care varied significantly by the underlying cause of death and closeness to day of death and is best represented graphically (Fig. 3). Periods of time enrolled in community-based specialist palliative care were clearly associated with reduced IA hospital costs for decedents with cancers, heart failure, chronic obstructive pulmonary disease and Alzheimer's disease (Fig. 3a-e).
For decedents with renal failure, Parkinson's disease and liver failure, the evidence of reduction in IA hospital costs with community-based specialist palliative care was only evident for parts of the last year of life (Fig. 3c-h). Decedents with motor neurone disease showed no significant difference in IA hospital costs with community-based specialist palliative care at any time over the last year of life (Fig. 3g).

\section{Discussion}

Cohort averaged hospital cost reductions associated with community-based specialist palliative care were evident across multiple life-limiting conditions; heart failure, renal failure, chronic obstructive pulmonary disease, liver failure, Parkinson's disease and cancer but not for motor neurone disease. Inpatient averaged hospital costs associated with community-based specialist palliative care were evident in the organ failures, Alzheimer's disease, chronic obstructive pulmonary disease and cancer but not in Parkinson's disease or motor neurone disease. The benefits of specialised palliative care for patients with non-cancer life limiting conditions are also reported to include reduced hospitalisation, improved symptom burden and quality of life [9-13]. Despite this, 


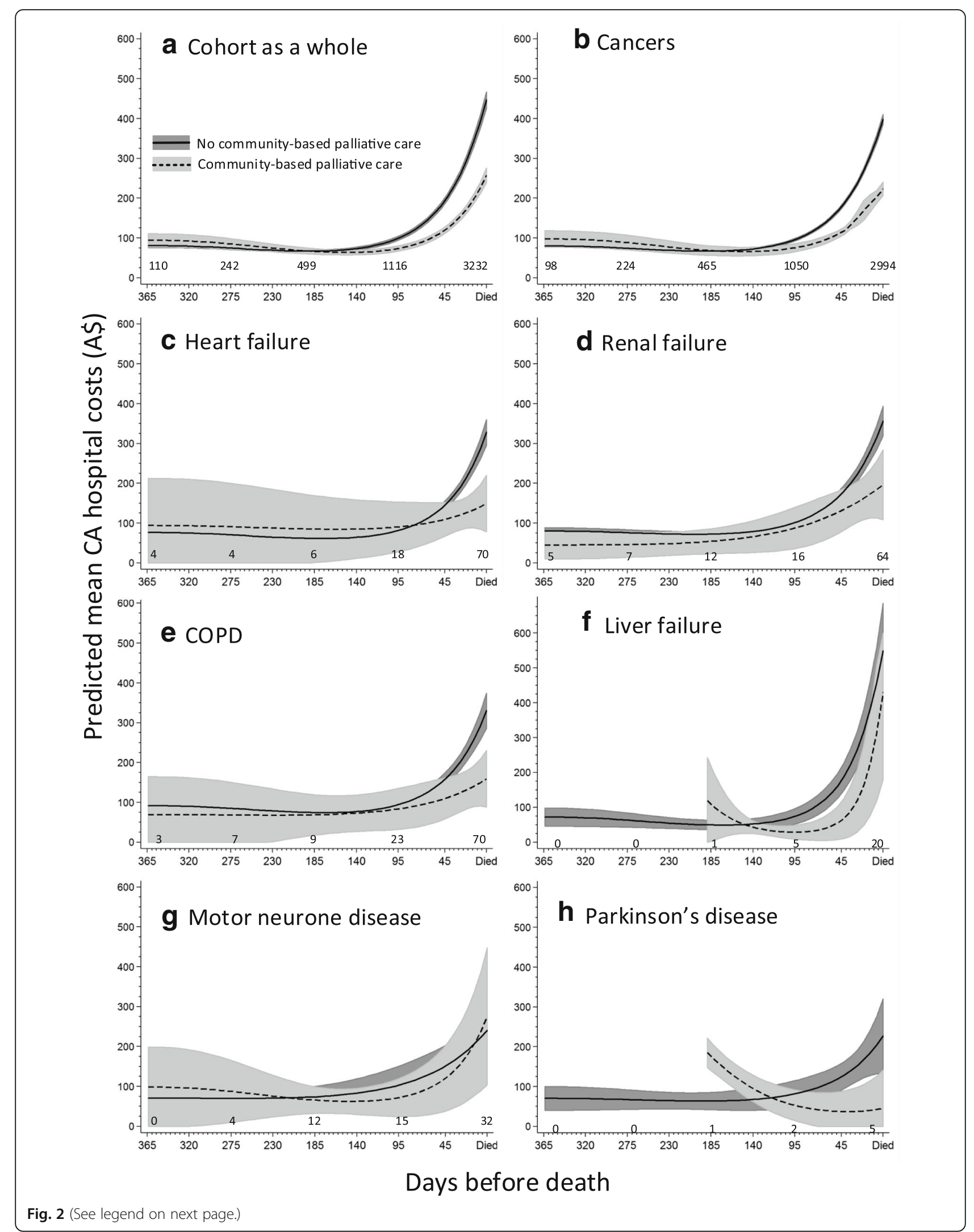


(See figure on previous page.)

Fig. 2 Predicted adjusted cohort averaged day-specific hospital costs by cause of death and community-based palliative care status. Estimated from a two part model that included an interaction term of periods of time receiving community-based palliative care with closeness to time of death and cause of death and adjusted for covariates in Table 1. The number of decedents receiving community-based palliative care on days 1 , 90, 180, 270 and 365 before death are indicated on each graph. Graphs were truncated until the time at least one decedent started receiving community-based palliative care and stable estimates could be obtained. The Sidak correction for multiple comparisons was applied. Shading represents $95 \%$ confidence intervals. ( $N=4,658,860$ days)

Table 2 Crude and adjusted inpatient averaged hospital costs stratified by decedent characteristics estimated over inpatient hospital days only

\begin{tabular}{|c|c|c|c|c|c|c|c|}
\hline \multirow{3}{*}{ Decedent characteristics } & & \multirow{3}{*}{$\begin{array}{l}\% \\
\text { of days }\end{array}$} & \multicolumn{5}{|c|}{ Inpatient averaged cost per decedent per day ( $n=451,210$ days) } \\
\hline & & & \multicolumn{2}{|c|}{ Crude A\$ } & \multicolumn{3}{|c|}{ Adjusted $^{a} \mathrm{~A} \$$} \\
\hline & & & $\overline{\text { Mean }}$ & SD & $\overline{M e a n}$ & $95 \% \mathrm{Cl}$ & $\mathrm{p}$ \\
\hline Receiving community & No & 88.5 & 1120 & 844 & 1126 & 1118-1134 & ref \\
\hline palliative care & Yes & 11.5 & 1064 & 435 & 1030 & 1021-1039 & $<0.001$ \\
\hline \multirow[t]{5}{*}{ Age group (years) } & $<60$ & 16.6 & 1166 & 992 & 1171 & 1147-1195 & ref \\
\hline & $60-69$ & 17.8 & 1154 & 918 & 1147 & $1127-1167$ & 0.109 \\
\hline & $70-79$ & 26.2 & 1126 & 849 & 1122 & $1106-1138$ & 0.001 \\
\hline & $80-89$ & 30.5 & 1075 & 649 & 1078 & 1067-1088 & $<0.001$ \\
\hline & $90+$ & 9.0 & 1032 & 480 & 1038 & 1023-1053 & $<0.001$ \\
\hline \multirow[t]{2}{*}{ Sex } & Male & 56.1 & 1130 & 851 & 1126 & 1116-1137 & ref \\
\hline & Female & 43.9 & 1093 & 748 & 1097 & 1086-1108 & $<0.001$ \\
\hline \multirow[t]{2}{*}{ Partnered } & No & 45.9 & 1091 & 765 & 1126 & 1094-1117 & ref \\
\hline & Yes & 54.1 & 1133 & 842 & 1097 & 1110-1130 & 0.070 \\
\hline \multirow[t]{2}{*}{ Private health insurance } & No & 56.4 & 1106 & 792 & 1110 & $1100-1120$ & ref \\
\hline & Yes & 43.6 & 1124 & 827 & 1118 & 1107-1130 & 0.286 \\
\hline \multirow[t]{3}{*}{ Residence at death } & Private residence & 86.5 & 1122 & 836 & 1116 & $1108-1124$ & ref \\
\hline & RACF & 10.8 & 1057 & 568 & 1099 & 1079-1118 & 0.130 \\
\hline & Other care/NFA & 2.7 & 1058 & 673 & 1094 & 1050-1138 & 0.358 \\
\hline \multirow[t]{8}{*}{ Underlying cause of death } & Neoplasms & 61.5 & 1143 & 779 & 1139 & 1130-1148 & ref \\
\hline & Heart failure & 13.6 & 1106 & 895 & 1130 & 1104-1156 & 0.569 \\
\hline & Renal failure & 12.4 & 982 & 799 & 979 & 950-1007 & $<0.001$ \\
\hline & COPD & 7.6 & 1097 & 871 & 1101 & 1066-1136 & 0.057 \\
\hline & Alzheimer's & 1.7 & 1096 & 471 & 1133 & 1101-1165 & 0.744 \\
\hline & Liver failure & 1.8 & 1221 & 1123 & 1164 & 1090-1238 & 0.503 \\
\hline & MND & 0.8 & 1061 & 591 & 1048 & $969-1127$ & 0.047 \\
\hline & Parkinson's & 0.7 & 1032 & 512 & 1036 & $997-1075$ & $<0.001$ \\
\hline \multirow[t]{6}{*}{ No. comorbid conditions } & None & 12.8 & 1085 & 636 & 1069 & 1057-1082 & ref \\
\hline & One & 16.3 & 1125 & 766 & 1106 & 1090-1123 & $<0.001$ \\
\hline & Two & 16.3 & 1125 & 768 & 1116 & 1100-1132 & $<0.001$ \\
\hline & Three & 14.1 & 1139 & 816 & 1134 & 1115-1153 & $<0.001$ \\
\hline & Four & 12.3 & 1131 & 919 & 1140 & $1114-1166$ & $<0.001$ \\
\hline & Five or more & 28.2 & 1094 & 865 & 1116 & 1098-1135 & $<0.001$ \\
\hline
\end{tabular}

RACF residential aged care facility, COPD chronic obstructive pulmonary disease, MND motor neurone disease, $S D$ standard deviation, NFA no fixed address, $A \$$

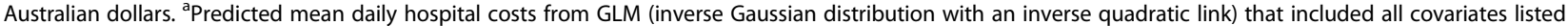
in table plus the closeness to time of death represented by day number 

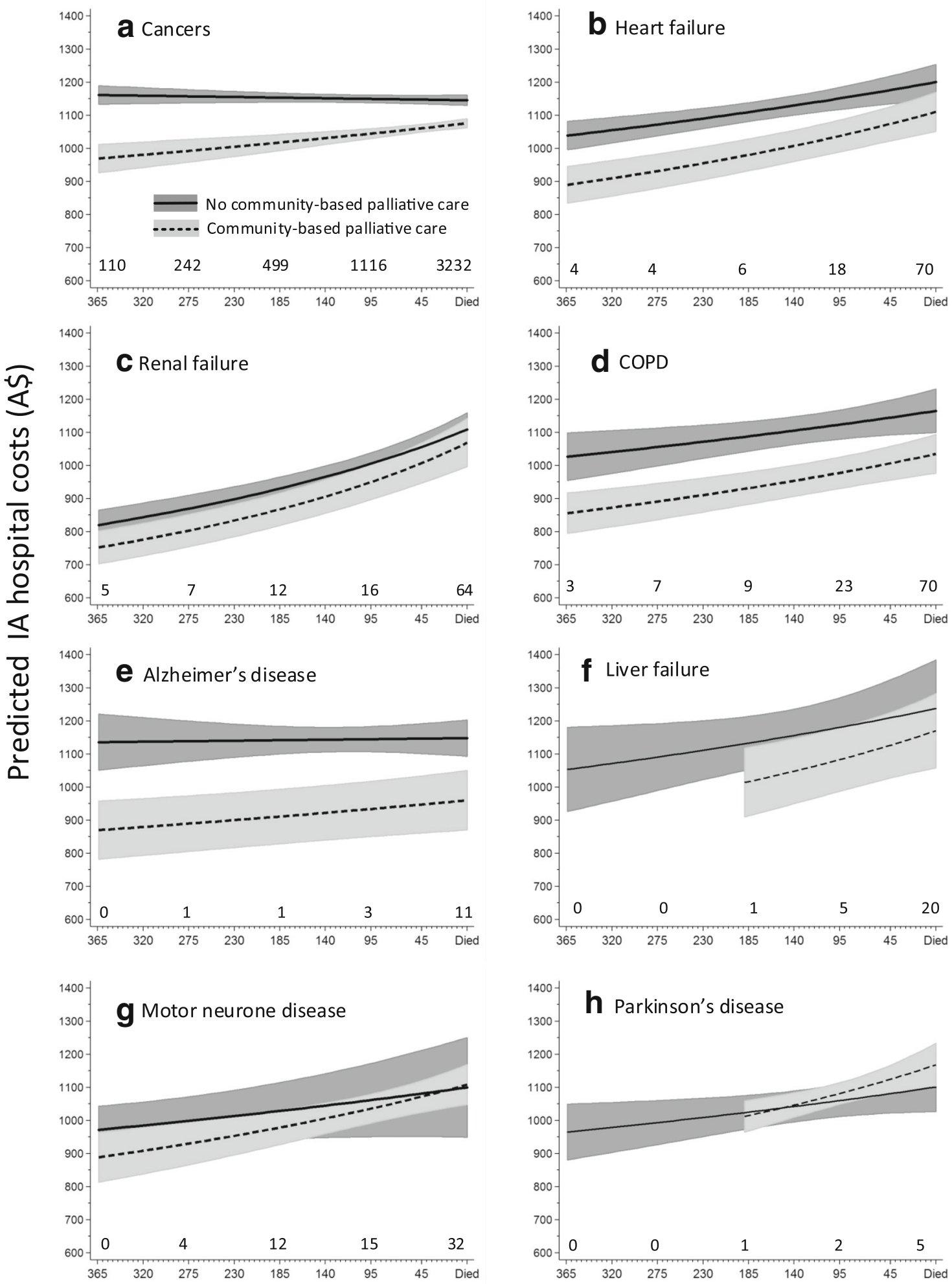

\section{Days before death}

Fig. 3 (See legend on next page.) 
(See figure on previous page.)

Fig. 3 Predicted inpatient averaged day-specific hospital costs by cause of death and community-based palliative care status. Predicted from an inverse Gaussian model adjusted for covariates in Table 2 with cause of death and closeness to time of death as interaction terms with community-based palliative care. Graphs were truncated until the time at least one decedent started receiving community-based palliative care and stable estimates could be obtained. Sidak correction for multiple comparisons applied and number of decedents enrolled in community-based palliative care on selected days indicated. Shading represents $95 \%$ confidence intervals. ( $N=451,210$ days)

palliative care in non-cancer life limiting conditions is generally reported as under-utilised [14-16].

We report an average $27 \%$ reduction in CA and an average $9 \%$ reduction in IA-specific hospital costs during periods of time enrolled in community-based specialist palliative care compared to periods of time not enrolled in this care over the last year of life. This suggests that receipt of community-based specialist palliative care affects both the decision to go to hospital and the hospital costs incurred once admitted, the latter likely a reflection of reduced lengths of hospital stays as we reported previously [28].

In general, the relative reduction in CA hospital costs continued to grow with closeness to time of death for most non-cancer conditions, a pattern observed by others in cancer patients $[29,30]$. These relative hospital cost reductions with community-based specialist palliative care were present as early as 4 to 5 months before death in decedents with cancer, but only as early as one or 2 months in most non-cancer conditions. This is partly due to the reduced power to detect cost differences with so few decedents with non-cancer conditions who accessed community-based specialist palliative care. We predict that in a much larger study, earlier hospital cost reductions in non-cancer conditions will be detected.

An exception to the trend of reduced hospital costs with community-based specialist palliative care in noncancer conditions was seen in decedents with motor neurone disease. This is possibly due to these decedents accessing community-based care through an alternative provider. The Motor Neurone Disease Association in WA is well established and assists clients through support and advisory services, access to specialist clinics, equipment support and accessible transport [31]. However, it is also possible that hospital costs associated with this life-limiting condition are less modifiable or less responsive to community-based specialist palliative care compared to other non-cancer conditions. Further work is needed to clarify this.

The strengths of this study were the large number of decedents from a population base and inclusion of multiple disease conditions amenable to palliative care. Our conclusions are widely generalizable in the Australian context and may also apply internationally where similar models of community-based specialist palliative care are employed. Limitations of this study included possible residual confounding by indication from the lack of clinical detail, particularly for non-hospitalised decedents, and motivations for accessing community-based specialist palliative care. It is likely that patients more accepting of the terminal nature of their condition were likely to receive palliative care and also have a higher threshold before accessing acute care services independent of the palliative care received. We were not able to distinguish between unmeasured patient inclinations and community-based specialist palliative care as drivers of reduced hospital costs in this study. However, a recent randomised controlled trial of cancer patients who were systematically provided with early palliative care resulted in less aggressive end-of-life care when compared to ondemand palliative care; suggesting palliative care itself can be a driver of less hospital use [6].

We also lacked information on the intensity of the palliative care delivered in this study. A dose response has been reported for home based palliative care in an Italian [32] and Canadian [33] setting, where more home nursing was associated with using less acute care services. We did not account for any possible carry over effect of specialist palliative care for decedents who were discharged from the service which may have biased the differences in costs in the week immediately following towards the null. We also presented our findings from a hospital payer perspective only that did not take account of the financial burden to carers and community-based service providers. It has been reported that the largest financial burden for home-based palliative care is the unpaid care costs of patients' carers [34]. Additional research on the costs of providing community-based specialist palliative care for different life-limiting conditions is also warranted. Our findings are based on data from 2009 to 2010, however, we have no reason to believe that relative hospital costs amongst patient subgroups would have changed significantly over that time.

It would also be naïve to assume that all decedents were willing or able to accept community-based specialist palliative care. While many studies report that most people would prefer to die at home rather than a hospital, there remains patients and carers who feel safer in hospital or have inadequate caring capacity at home [35].

\section{Conclusion}

Community-based palliative care was associated with reduced hospital costs in the last year of life in non-cancer 
life-limiting medical conditions. Our findings provide further evidence to encourage adoption of communitybased specialist palliative care across multiple lifelimiting conditions. In an environment of limited health resources, these results should encourage policy makers and service providers to target delivery of palliative care services to all people who could benefit, not just those with cancer.

\section{Abbreviations}

AS: Australian dollar; AR-DRG: Australian Refined-Diagnostic Related Groups: CA: Cohort averaged; IA: Inpatient averaged; NHCDC: National Hospital Cost Data Collection; RACF: Residential aged care facility; WA: Western Australia

\section{Acknowledgements}

The authors wish to thank the staff at the WA Data Linkage Branch and the custodians of the Hospital Morbidity Data Collections, the Births, Deaths and Marriages register and the Silver Chain community care group for access to and linkage of their data.

\section{Funding}

This study was supported by an Australian National Health and Medical Research Council project grant (\#1029663). The funding body had no role in the collection of data, analysis, interpretation or manuscript writing.

\section{Availability of data and materials}

Data in this study was accessed through the WA Data Linkage Branch based in the WA Department of Health. Release of a de-identified data to researchers requires both ethical approval from both the Department of Health Human Research Ethics Committee and the institutional Human Research Ethics Committee where the research will be conducted. In addition, data custodian approvals may be required. Data requests may be sent to:

Department of Health WA Human Research Ethics Committee (EC00422). Department of Health.

Level 1, C Block

189 Royal Street.

EAST PERTH WA 6004

Phone: +61 892224278

Email: hrec@health.wa.gov.au

\section{Authors' contributions}

LR conceived and designed the study, obtained research funding and critically reviewed the manuscript. KS conducted the statistical analysis and drafted the manuscript. Both authors read and approved the final manuscript.

\section{Ethics approval and consent to participate}

Approvals to conduct this study under a waiver of consent were granted by Human Research Ethics Committees at the WA Department of Health (\#2012/ 76, approval date 01/02/2013) and Curtin University (53/2012, approval date 06/ 06/2012).

\section{Consent for publication}

Not applicable.

\section{Competing interests}

The authors declare that they have no competing interests.

\section{Publisher's Note}

Springer Nature remains neutral with regard to jurisdictional claims in published maps and institutional affiliations.

\section{Author details}

${ }^{1}$ Centre for Population Health Research, Faculty of Health Sciences, Curtin University, Perth, Australia. ${ }^{2}$ School of Occupational Therapy and Social Work, Faculty of Health Sciences, Curtin University, GPO Box U1987, Perth 6845, Australia.
Received: 29 August 2017 Accepted: 30 November 2017

Published online: 08 December 2017

\section{References}

1. Aldridge MD, Kelley AS. The myth regarding the high cost of end-of-life care. Am J Public Health. 2015;105(12):2411-5.

2. Stooker T, van Acht JW, van Barneveld EM, van Vliet RC, van Hout BA, Hessing DJ, Busschbach JJ. Costs in the last year of life in The Netherlands. Inquiry. 2001;38(1):73-80.

3. Tanuseputro $P$, Wodchis WP, Fowler R, Walker $P$, Bai $Y Q$, Bronskill SE, Manue $D$. The health care cost of dying: a population-based retrospective cohort study of the last year of life in Ontario, Canada. PLoS One. 2015;10(3): e0121759.

4. Chang CM, CC W, Yin WY, Juang SY, CH Y, Lee CC. Low socioeconomic status is associated with more aggressive end-of-life care for working-age terminal cancer patients. Oncologist. 2014;19(12):1241-8.

5. Shinall MC, Jr., Ehrenfeld JM, Guillamondegui OD: Religiously affiliated intensive care unit patients receive more aggressive end-of-life care. I Surg Res 2014, 190(2):623-627

6. Maltoni M, Scarpi E, Dall'Agata M, Schiavon S, Biasini C, Codeca C, Broglia CM, Sansoni E, Bortolussi R, Garetto F, et al. Systematic versus on-demand early palliative care: a randomised clinical trial assessing quality of care and treatment aggressiveness near the end of life. Eur J Cancer. 2016;69:110-8.

7. Smith S, Brick A, O'Hara S, Normand C. Evidence on the cost and costeffectiveness of palliative care: a literature review. Palliat Med. 2014; 28(2):130-50.

8. Emanuel EJ, Ash A, Yu W, Gazelle G, Levinsky NG, Saynina O, McClellan M, Moskowitz M. Managed care, hospice use, site of death, and medical expenditures in the last year of life. Arch Intern Med. 2002;162(15):1722-8.

9. Baumann AJ, Wheeler DS, James M, Turner R, Siegel A, Navarro VJ. Benefit of early palliative care intervention in end-stage liver disease patients awaiting liver transplantation. J Pain Symptom Manag. 2015;50(6):882-6. e882

10. Brannstrom M, Boman K. Effects of person-centred and integrated chronic heart failure and palliative home care. PREFER: a randomized controlled study. Eur J Heart Fail. 2014;16(10):1142-51.

11. Chan KY, Cheng HW, Yap DY, Yip T, Li CW, Sham MK, Wong YC, Lau WK Reduction of acute hospital admissions and improvement in outpatient attendance by intensified renal palliative care clinic follow-up: the Hong Kong experience. J Pain Symptom Manag. 2015:49(1):144-9.

12. Iupati SP, Ensor BR. Do community hospice programmes reduce hospitalisation rate in patients with advanced chronic obstructive pulmonary disease? Intern Med J. 2016;46(3):295-300.

13. Pouliot K, Weisse CS, Pratt DS, DiSorbo P. First-year analysis of a new, homebased palliative care program offered jointly by a community hospital and local visiting nurse service. Am J Hosp Palliat Care. 2015;

14. Hess S, Stiel S, Hofmann S, Klein C, Lindena G, Ostgathe C. Trends in specialized palliative care for non-cancer patients in Germany-data from the national hospice and palliative care evaluation (HOPE). Eur J Intern Med. 2014;25(2):187-92

15. Robinson MR, Al-Kindi SG, Oliveira GH. Trends in palliative care use in elderly men and women with severe heart failure in the United States. JAMA Cardiol. 2017;2(3):344.

16. Rosenwax L, Spilsbury K, McNamara B, Semmens JB. A retrospective population based cohort study of access to specialist palliative care in the last year of life: who is still missing out a decade on? BMC Palliative Care. 2016:15

17. Spilsbury K, Rosenwax L, Arendts G, Semmens JB. The Association of Community-Based Palliative Care with Reduced Emergency Department Visits in the last year of life varies by patient factors. Ann Emerg Med. 2017; 69(4):416-25.

18. Rosenwax LK, McNamara BA. Who receives specialist palliative care in Western Australia-and who misses out. Palliat Med. 2006;20(4):439-45

19. Silver Chain Group. Palliative Care. Perth; 2017

20. Australian Consortium for Classification Development: Australian refined diagnostic related groups (AR-DRG).

21. Commonwealth Department of Health and Ageing. National Hospital Cost Data Collection Cost Report Rount 13 (2008-2009). Canberra: Commonwealth of Australia; 2010.

22. Commonwealth Department of Health and Ageing. Round 14 version 6 final service cost weights. Canberra: Commonwealth of Australia; 2011. 
23. Ishak KJ, Stolar M, MY H, Alvarez P, Wang Y, Getsios D, Williams GC. Accounting for the relationship between per diem cost and LOS when estimating hospitalization costs. BMC Health Serv Res. 2012;12:439.

24. Independent Hospital Pricing Authority. National Hospital Cost Data Collection Australian Public Hospitals Cost Report 2010-2011, round 15. Sydney: Commonwealth of Australia; 2013.

25. Glover J, Tennant S. Remote areas statistical geography in Australia: notes on the accessibility/remoteness index for Australia (ARIA + version). In., vol. working paper series no. 9. Adelaide: Public Health Information Development Unit; 2003

26. Elixhauser A, Steiner C, Harris DR, Coffey RM. Comorbidity measures for use with administrative data. Med Care. 1998;36(1):8-27.

27. Quan H, Sundararajan V, Halfon P, Fong A, Burnand B, Luthi JC, Saunders $L D$, Beck CA, Feasby TE, Ghali WA. Coding algorithms for defining comorbidities in ICD-9-CM and ICD-10 administrative data. Med Care. 2005; 43(11):1130-9.

28. Spilsbury K, Rosenwax L, Arendts G, Semmens JB. The impact of communitybased palliative care on acute hospital use in the last year of life is modified by time to death, age and underlying cause of death. A population-based retrospective cohort study. PLoS One. 2017;12(9):e0185275.

29. Tamir $O$, Singer $Y$, Shvartzman P. Taking care of terminally-ill patients at home - the economic perspective revisited. Palliat Med. 2007:21(6):537-41.

30. Youens D, Moorin R. The impact of community-based palliative care on utilization and cost of acute Care Hospital Services in the Last Year of life. J Palliat Med. 2017;

31. MND Western Australia [http://www.mndawa.asn.au/Content/home].

32. Ferroni E, Avossa F, Figoli F, Cancian M, De Chirico C, Pinato E, Pellizzari M, Fedeli U, Saugo M, Mantoan D. Intensity of integrated primary and specialist home-based palliative Care for Chronic Diseases in Northeast Italy and its impact on end-of-life hospital access. J Palliat Med. 2016;19(12):1260-6.

33. Seow H, Barbera L, Howell D, Dy SM. Using more end-of-life homecare services is associated with using fewer acute care services: a populationbased cohort study. Med Care. 2010:48(2):118-24.

34. Chai H, Guerriere DN, Zagorski B, Coyte PC. The magnitude, share and determinants of unpaid care costs for home-based palliative care service provision in Toronto, Canada. Health Soc Care Community. 2014;22(1):30-9.

35. Reyniers T, Deliens L, Pasman HR, Vander Stichele R, Sijnave B, Cohen J, Houttekier D. Reasons for end-of-life hospital admissions: results of a survey among family physicians. J Pain Symptom Manag. 2016:52(4):498-506.

\section{Submit your next manuscript to BioMed Central and we will help you at every step:}

- We accept pre-submission inquiries

- Our selector tool helps you to find the most relevant journal

- We provide round the clock customer support

- Convenient online submission

- Thorough peer review

- Inclusion in PubMed and all major indexing services

- Maximum visibility for your research

Submit your manuscript at www.biomedcentral.com/submit

) Biomed Central 